\section{Use of Polyethylene and Plastic Biodegradable Mulches among Tennessee Fruit and Vegetable Growers}

\author{
Margarita Velandia ${ }^{1}$, Karen L. DeLong ${ }^{1}$, Annette Wszelaki ${ }^{2}$, \\ Susan Schexnayder ${ }^{3}$, Christopher Clark ${ }^{1}$, and Kimberly Jensen ${ }^{1}$
}

ADDITIONAL INDEX WORDs. mulch disposal, plastic mulches, soil plastic pollution, Tennessee farmers' survey, willingness to pay for biodegradable mulches

Summary. Polyethylene (PE) mulch provides significant benefits to fruit and vegetable producers because it has the potential to improve crop quality and increase yield. However, the use of PE mulch generates plastic pollution, posing challenges to the sustainability of fruit and vegetable production. Plastic biodegradable mulches (BDMs) are a sustainable alternative to $\mathrm{PE}$ mulch because they are designed to decompose into water, carbon dioxide, and microbial biomass. We surveyed Tennessee fruit and vegetable growers to assess their use of PE mulch, BDM, or both; the differences in the characteristics of BDM users and nonusers; and their interest in using BDM. Our results indicate a large percentage of fruit and vegetable growers have used PE mulch compared with BDM. In general, BDM users tend to have more acres in fruit and vegetable production, have used dumping and burying as PE mulch disposal methods, and have spent more hours removing and disposing of PE mulch. Results indicate that even at prices higher than the current average market price for BDM, there is a percentage of Tennessee fruit and vegetable growers interested in using BDM.

$\mathrm{P}$ olyethylene mulch is traditionally used in the production of some fruits and vegetables to maintain soil moisture and increase soil temperature, control weeds, improve crop quality, and increase yield (Emmert, 1957). In the United States, 1 billion pounds of plastic are used every year in the production of crops (Fessenden, 2015). It is estimated that in vegetable production alone, U.S. farmers are using about 143,300 tons of PE mulch per year (Shogren and Hochmuth, 2004).

Received for publication 17 Dec. 2019. Accepted for publication 24 Jan. 2020.

Published online 20 February 2020.

${ }^{1}$ Department of Agricultural and Resource Economics, the University of Tennessee, 2621 Morgan Circle, 314C Morgan Hall, Knoxville, TN 37996

${ }^{2}$ Department of Plant Sciences, the University of Tennessee, 2505 E J Chapman Drive, 112 Plant Biotech Building, Knoxville, TN 37996

${ }^{3}$ Department of Forestry, Wildlife, and Fisheries, the University of Tennessee, 2431 Joe Johnson Drive, 274 Ellington Plant Sciences Building, Knoxville, TN 37996

This work was supported by the U.S. Department of Agriculture National Institute of Food and Agriculture Specialty Crop Research Initiative (award no. 2014-51181-22382).

M.V. is the corresponding author. E-mail: mvelandi@ utk.edu.

This is an open access article distributed under the CC BY-NC-ND license (https://creativecommons.org/ licenses/by-nc-nd/4.0/).

https://doi.org/10.21273/HORTTECH04559-19
Recycling options for PE mulch after using it are limited because it gets contaminated with soil and vegetation, as well as chemicals such as pesticides and fungicides during the cropping season, and many recycling facilities will not accept it. Also, transportation of used plastic to recycling facilities can be challenging, and the recycling facilities that can and will accept it are limited in their capacity to process it (Moore and Wszelaki, 2016). Given the limited recycling opportunities, farmers resort to disposing of PE mulch at landfills or other even less desirable disposal methods (e.g., burning). At the end of season, farmers remove PE mulch and dispose of it in landfills, stockpile it on the farm, or burn it on site (Kasirajan and Ngouajio, 2012). Regardless of the benefits associated with the use of PE mulch in fruit and vegetable production, the use of this mulch is not considered environmentally sustainable because the ways in which farmers dispose of PE mulch often contribute to soil and air pollution. For example, when burned on site, PE mulches release carcinogenic substances that could negatively affect human health (Valavanidis et al., 2008).

Additionally, the use of PE mulch is not considered environmentally sustainable because at the end of the season, it is difficult to completely remove this mulch, and the mulch fragments left behind contribute to soil plastic pollution in the long-term. Soil plastic pollution could negatively affect soil productivity and therefore farm profitability (Liu et al., 2014).

Plastic BDMs provide similar benefits to PE mulch, but they are considered more sustainable than PE mulch (Goldberger et al., 2019). At the end of the season, BDMs do not have be removed, but rather they can be tilled into the soil or composted onsite, since they are designed to decompose in soil conditions into water, carbon dioxide, and microbial biomass (Hayes and Flury, 2018). The use of BDM has the potential not only to reduce the negative environmental impacts associated with the use of $\mathrm{PE}$ mulch but also to reduce labor associated with PE mulch removal and disposal activities. The potential labor savings from the use of $\mathrm{BDMs}$ are important in farmers' assessment of the economic feasibility of transitioning from $\mathrm{PE}$ mulch to BDM because $\mathrm{BDM}$ is more expensive than $\mathrm{PE}$ mulch (Velandia et al., 2019).

There are only two studies exploring the use of BDM and PE mulch among U.S. fruit and vegetable growers (Goldberger et al., 2013, 2019). Using a qualitative approach, Goldberger et al. (2013) explored the use of plastic mulch among fruit and vegetable growers in Tennessee, Washington, and Texas, and the perceived bridges and barriers to BDM adoption among these growers. Goldberger et al. (2019) evaluate regional differences in producers' opinions about PE mulch and BDM. None

\begin{tabular}{lllc}
\hline $\begin{array}{l}\text { Units } \\
\begin{array}{l}\text { To convert U.S. to SI, } \\
\text { multiply by }\end{array}\end{array}$ & U.S. unit & SI unit & $\begin{array}{l}\text { To convert SI to U.S., } \\
\text { multiply by }\end{array}$ \\
\hline 0.4047 & $\mathrm{acre}(\mathrm{s})$ & $\mathrm{ha}$ & 2.4711 \\
0.3048 & $\mathrm{ft}$ & $\mathrm{m}$ & 3.2808 \\
0.4536 & $\mathrm{lb}$ & $\mathrm{kg}$ & 2.2046 \\
0.0254 & $\mathrm{mil}(\mathrm{s})$ & $\mathrm{mm}$ & 39.3701 \\
0.9072 & $\mathrm{mon}(\mathrm{s})$ & $\mathrm{Mg}$ & 1.1023
\end{tabular}


of these studies evaluate the differences in the characteristics of those farmers who have used BDM and those who have mainly used PE mulch for the production of fruit and vegetables. Only one study has explored the influence of BDM prices in fruit and vegetable growers' willingness to use this type of mulch (Scaringelli et al., 2016).

Using data from a survey of Tennessee fruit and vegetable growers, we evaluated: 1) the use of PE mulch among Tennessee fruit and vegetable growers and their use of or interest in using BDM; 2) the differences in the characteristics of those who had used BDM and those who have used PE mulch only for the production of fruit and vegetables; and 3 ) Tennessee fruit and vegetable growers willingness to use BDM at various price levels.

\section{Materials and methods}

We conducted a survey of Tennessee fruit and vegetable growers between Jan. and Apr. 2019. The survey instrument was approved by the University of Tennessee Institutional Review Board (UTK IRB-18-04718XM). We used a mix-mode survey with Web and paper versions to improve response rates and reduce coverage and nonresponse error (Dillman et al., 2009). We sent a Web version of the survey on 29 Jan. 2019 to individuals for whom we had e-mail addresses. Following the tailored design method (Dillman et al., 2009), we sent reminder e-mails on 5 and 12 Feb. 2019. A paper version of the survey was mailed on 20 Mar. 2019, and reminders and follow-up surveys were sent on 30 Mar. 2019, and 5 Apr. 2019, respectively, to individuals for whom we did not have e-mail addresses or had invalid e-mail addresses, and to those that did not respond to the Web survey. The paper and online versions of the survey instrument contained identical questions.

The survey included between 22 and 34 questions, depending on respondents' answers. Depending on their answers, respondents were directed to different sections of the survey. We estimated that it would take 20 to $25 \mathrm{~min}$ to complete the survey. More than $50 \%$ of the survey questions were multiple choice; we only had a few open-ended questions. Survey questions were associated with respondent years of experience using PE mulch and/or BDM; satisfaction with and reasons for using or not using PE mulch and/or BDM; disposal methods of $\mathrm{PE}$ mulch; labor hours associated with the removal and disposal of PE mulch; familiarity with and willingness to use BDMs at various price points; and questions capturing respondents environmental stewardship and risk preferences. Additionally, we asked individuals questions to elicit general farmer and farm business characteristics, such as farmer age, farming experience, education, acres in fruit and vegetable production, and gross farm revenue. We only present information from questions that address the objectives presented in the introduction section.

The contact list of fruit and vegetable producers used to conduct the survey was provided by the Tennessee Department of Agriculture. The contact list included farmers who participated in 2018 in either a program that aims to assist Tennessee farmers in marketing (i.e., Pick Tennessee Products) or a program that provides costshare for farm improvements (i.e., Tennessee Ag Enhancement). The final contact list after removing duplicate e-mail and mail addresses included 990 fruit and vegetable farmers. From this initial list, 98 farmers indicated that they do not farm, 135 had e-mail or mailing addresses that were marked as undeliverable, 2 indicated they were not fruit and vegetable growers, 1 was retired from farming, and 1 was ill and unable to complete the survey. There were 186 completed surveys (i.e., 91 online and 95 mail surveys), for a survey response rate of $25 \%$. Survey respondents represented farms from various counties across west, middle, and east Tennessee (Fig. 1).

We evaluated the representativeness of the survey sample by comparing the distribution of the survey sample based on acres in vegetable production to the distribution of Tennessee vegetable growers based on the 2017 Census of Agriculture data [U.S. Department of Agriculture (USDA), 2019]. The 2017 Census of Agriculture reports acres in vegetable, fruit and nuts, and berry production separately. A large percentage of our survey respondents indicated either growing only vegetables or vegetables and fruits and berries. Therefore, we consider acres in vegetable production a good basis for comparison. The farm size distribution from the survey sample follows closely the farm size distribution of vegetable farms in
Tennessee (Fig. 2). Overall, a large percentage $(82 \%)$ of Tennessee vegetable farms are small, with reported areas in vegetable production between 0.1 and 4.9 acres (Fig. 2). The survey sample tends to slightly overrepresent vegetable farms between 5 and 49.9 acres (32\%) and underrepresent farms between 0.1 and 4.9 acres (66\%). Because the survey focuses on the use of PE mulch among fruit and vegetable farms in Tennessee, it is likely that growers with larger farms were more likely to respond to the survey, given that these farms are more likely to use PE mulch. There are alternative mulch options that provide similar benefits to PE mulch but are more suitable for small-scale production systems such as straw and landscape fabric (Feldman et al., 2000; Schonbeck, 2015). Therefore, we hypothesized that larger operations may be more likely to use PE mulch for the production of fruit and vegetable crops.

Analysis. We used independent-samples $t$ tests to evaluate differences in selected farmer and farm business characteristics between BDM users and nonusers, captured by continuous variables. For farm and farm business characteristics captured by dichotomous variables, we used an equality proportion test (StataCorp, 2013) to evaluate statistical differences in these characteristics between BDM users and nonusers.

To determine what producers were willing to pay for BDMs, we asked them about their preferences between PE mulch and BDM based on information about how these mulches can be laid, end-of-season activities associated with each mulch, and different price levels (Table 1 ). We used a base price of $\$ 100$ for a $4 \times 4000-\mathrm{ft}$ roll of black PE mulch with a thickness of 1 mil, based on the lowest PE mulch price a grower could pay according to the current market prices (Velandia et al., 2019). We randomly assigned survey participants one of four price levels for a $4 \times 4000$ - $\mathrm{ft}$ roll of black BDM that included $\$ 100$ (assigned to 48 respondents), $\$ 200$ (assigned to 51 respondents), $\$ 250$ (assigned to 48 respondents), or $\$ 300$ (assigned to 43 respondents) (Table 3). Prices were chosen based on actual market prices for BDMs (Velandia et al., 2019). The price of BDMs varies by thickness, type, and input supplier. There is also a potential additional shipping cost that we did not include in these prices. 


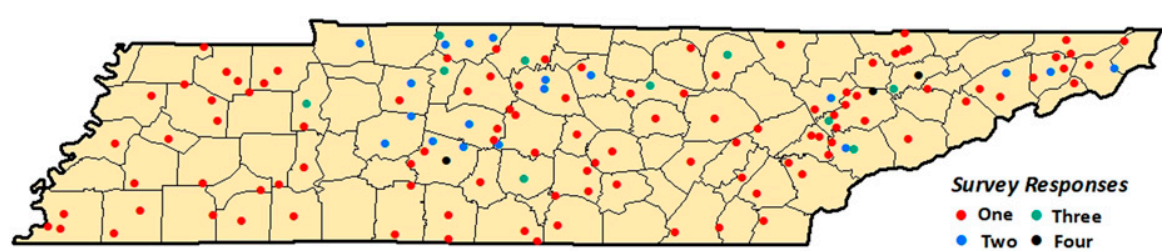

Fig. 1. Respondents to a 2019 survey of Tennessee fruit and vegetable farmers about the use of polyethylene (PE) mulch and plastic biodegradable mulch (BDM) based on zip code (red dots represent locations with only one response, and the blue, green, and black dots represent locations with two, three, and four responses, respectively).

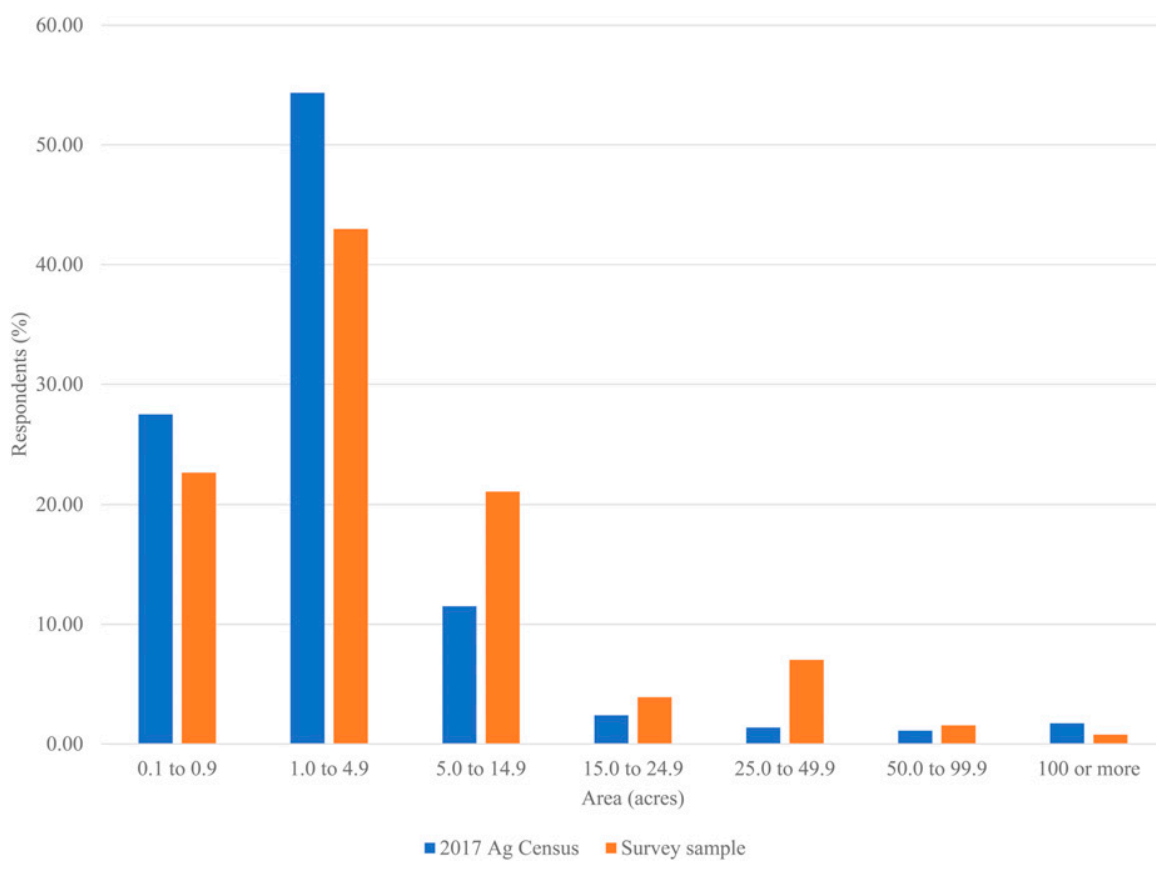

Fig. 2. Percentage of farms in each farm size category based on acres in vegetable production according to the 2017 Census of Agriculture data (USDA, 2019) and the survey sample from a 2019 survey of Tennessee fruit and vegetable farmers about the use of polyethylene (PE) mulch and plastic biodegradable mulch $(\mathrm{BDM}) ; 1$ acre $=0.4047$ ha.

\section{Results and discussion}

FARMER AND FARM BUSINESS CHARACTERISTICS. Respondents to the survey were 57 years old, on average, which is close to the average age of farmers in Tennessee (i.e., 58 years), according to the 2017 Census of Agriculture (USDA, 2019). Approximately $60 \%$ of the survey respondents indicated having a bachelors' degree and $81 \%$ of Tennessee fruit and nuts' farms have less than $\$ 25,000$ in farm sales, which suggests a larger percentage of Tennessee fruit and vegetable farms have less than $\$ 25,000$ in onfarm revenue than those captured by the survey sample. It is important to acknowledge that the 2017 Census of Agriculture (USDA, 2019) does not provide information about overall onfarm revenue for fruit and vegetable farms, but it only provides information about farm vegetable, fruit, and nut sales. There could be diversified fruit and vegetable farms, where gross on-farm revenue includes revenue generated from the sales of fruits and vegetables but also sales associated with other farm enterprises (e.g., livestock), and therefore, census data are not necessarily capturing gross on-farm revenue.

USE AND DISPOSAL OF PE MULCH. Approximately $60 \%$ of the survey respondents indicated that they had used PE mulch on their farm (Table 1). The remaining $40 \%$ had likely not used any mulch or other mulch products such as landscape fabric or straw (Feldman et al., 2000; Schonbeck, 2015). PE mulch users indicated they had used this type of mulch for an average of 10 years.

Most of the acres captured by this survey are in tomato (Solanum lycopersicum), watermelon (Citrullus lanatus), and pumpkin (Cucurbita pepo), with $34 \%, 11 \%$, and $8 \%$ of the total acres reported in tomato, pumpkin, and watermelon production, respectively. Strawberry (Fragaria Xananassa), tomato, watermelon, and cantaloupe (Cucumis melo var. cantalupensis) had a fairly high percentage of acres grown on PE mulch compared with other crops, with an average of $59 \%, 55 \%$, $54 \%$, and $50 \%$ of acres in cantaloupe, strawberry, watermelon, and tomato, respectively, grown on PE mulch (Fig. $3)$. These results suggest that strawberry, tomato, watermelon, and cantaloupe are the crops more likely to be grown using PE mulch.

Respondents indicated they dispose of PE mulch at landfills (75\%), by burying them on-site (15\%), and/or by burning them $(22 \%)$. This last disposal method maybe understated, given that burning $\mathrm{PE}$ mulch is illegal in Tennessee (Velandia et al., 2019). Some producers (15\%) use more than one method for disposing of PE mulch. Respondents estimated that activities 
Table 1. Summary statistics for selected farmer and farm business characteristics, and farmer use and disposal of mulches based on data from a 2019 survey of Tennessee fruit and vegetable farmers about the use of polyethylene (PE) mulch and plastic biodegradable mulch (BDM).

\begin{tabular}{|c|c|c|c|c|c|}
\hline Variable $^{\mathrm{z}}$ & $\mathbf{n}$ & Mean & SD & Minimum & Maximum \\
\hline PE_USE $=1$ if farmer has used PE mulch & 184 & 0.60 & & 0 & 1 \\
\hline BDM_USE = 1 if farmer has used BDM & 181 & 0.15 & & 0 & 1 \\
\hline EXP_PE - years using PE mulch & 108 & 9.74 & 9.89 & 1 & 50 \\
\hline EXP_BDM - years using BDM & 31 & 1.42 & 1.20 & 0 & 6 \\
\hline $\begin{array}{l}\text { Labor (h/acre): labor hours associated with removal } \\
\text { and disposal of PE mulch in hours per acre }\end{array}$ & 101 & 17.25 & 15.84 & 0 & 80 \\
\hline $\begin{array}{l}\text { Burying = } 1 \text { if farmer indicated burying PE mulch } \\
\text { in the field after using it. }\end{array}$ & 110 & 0.15 & & 0 & 1 \\
\hline $\begin{array}{l}\text { Burning }=1 \text { if farmer indicated burning PE mulch } \\
\text { after using it. }\end{array}$ & 110 & 0.22 & & 0 & 1 \\
\hline Age (years) & 178 & 56.85 & & 1 & 60 \\
\hline Experience farming (years) & 185 & 19.89 & & 1 & 60 \\
\hline $\begin{array}{l}\text { Farming income }<\$ 25,000=1 \text { if annual gross on- } \\
\text { farm revenue is }<\$ 25,000\end{array}$ & 84 & 0.52 & & 0 & 1 \\
\hline $\begin{array}{l}\text { Farming income }>\$ 25,000=1 \text { if annual gross on- } \\
\text { farm revenue is }>\$ 25,000\end{array}$ & 84 & 0.48 & & 0 & 1 \\
\hline
\end{tabular}

${ }^{\mathrm{z}} 1 \mathrm{~h} /$ acre $=2.4711 \mathrm{~h} \cdot \mathrm{ha}^{-1}, \mathrm{l}$ acre $=0.4047$ ha.

Table 2. Selected variable means for plastic biodegradable mulch (BDM) users and nonusers and statistical significance of mean differences based on independent-samples $t$ tests and equality proportion tests using data from a 2019 survey of Tennessee fruit and vegetable farmers about the use of polyethylene (PE) mulch and BDM.

\begin{tabular}{lcr}
\hline Variable $^{\mathrm{z}}$ & BDM users $(\mathbf{n}=\mathbf{2 6})$ & Users of PE mulch only $(\mathbf{n}=\mathbf{8 2})$ \\
\hline Age & 55.38 & 55.81 \\
Experience farming & $23.46^{*}$ & 18.93 \\
BS degree or higher & $0.46^{* *}$ & 0.66 \\
Farm size_F\&V (fruit and vegetable in acres) & $19.18^{* * *}$ & 7.31 \\
Farming income $>\$ 25,000$ & 0.64 & 0.49 \\
Dumping & $0.62^{* *}$ & 0.81 \\
Burying & $0.23^{*}$ & 0.11 \\
Burning & 0.31 & 0.19 \\
Labor (hours/acre) & $21.38^{*}$ & 15.73 \\
\hline
\end{tabular}

${ }^{\mathrm{z}} 1$ acre $=0.4047 \mathrm{ha}, 1 \mathrm{~h} /$ acre $=2.471 \mathrm{l} \mathrm{h} \cdot \mathrm{ha}^{-1}$.

${ }^{*},{ }^{* *},{ }^{* *}$ Significant at $P \leq 0.10,0.05$, or 0.01 , respectively.

related to the removal and disposal of $\mathrm{PE}$ mulch took an average of $17 \mathrm{~h} /$ acre, with a minimum of 0 and a maximum of $80 \mathrm{~h} /$ acre associated with this end-of-season activities. A farmer will be saving, on average, $\approx 17 \mathrm{~h} /$ acre when using BDM, according to the results presented here, and eliminating disposal costs. Farmers need to be aware of these potential savings to evaluate the economic feasibility of adopting BDM (Velandia et al., 2019).

The estimated average labor hours associated with removal and disposal of PE mulch based on the survey results seem to be higher than the estimated labor hours based on data collected from three Tennessee fruit and vegetable farms between 2017 and 2018 (Velandia et al., 2018). As stated by Velandia et al. (2018) removal practices could vary from farm to farm, and that may explain the differences in labor hour estimates. For example, after manually removing $\mathrm{PE}$ mulch, there are mulch fragments left behind that farmers may or may not retrieve depending on labor availability and their beliefs regarding the impact these mulch fragments could have on soil quality (Velandia et al., 2018).

FamiliaRity WITH AND USE OF BDMs. We asked respondents to indicate their familiarity with BDMs. Approximately 33\% of the survey respondents were not familiar with BDMs, $61 \%$ indicated they were slight to moderately familiar with BDMs, and $6 \%$ of survey respondents indicated being very familiar with BDMs. Approximately $15 \%$ of the respondents indicated they had used BDMs. Those who had used BDMs had done so for an average of 1 year 
and 5 months (Table 1 ). It is important to acknowledge that farmers who indicated they had used BDMs in the past could have used mulches that are incorrectly labeled as BDMs but are oxo- or photo-degradable plastic mulches, which fragment with ultraviolet exposure but do not biodegrade in the soil (Miles, 2017). Bad experience with these as BDMs could partially explain why the average years of BDM use are mulches that are wrongly advertised

low among those farmers who indicated using BDMs.

DIFFERENCES BETWEEN BDM USERS AND NONUSERS. Table 2 presents comparisons of producer and farm business characteristics relative to BDM users who have also used PE mulch, and producers who have used PE mulch but have never used BDM. We focused on the use of BDM among growers who have previous experience with PE mulch, as one of the main benefits of transitioning

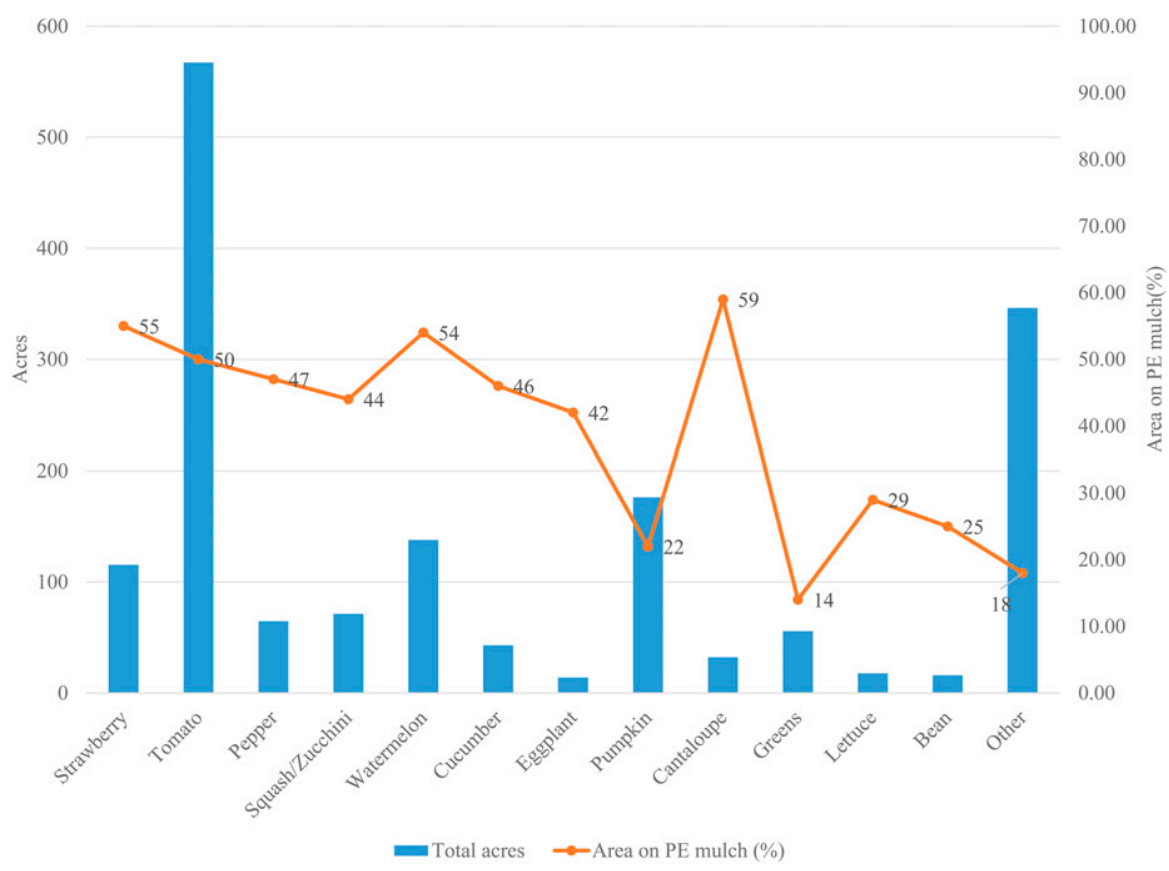

Fig. 3. Total acres in crops reported by respondents to a 2019 survey of Tennessee fruit and vegetable farmers about the use of polyethylene (PE) mulch and plastic biodegradable mulch (BDM), and average percentage of acres on PE mulch by crop including cantaloupe (Cucumis melo var. cantalupensis), cucumber (Cucumis sativus), eggplant (Solanum melongena), greens [e.g., kale (Brassica oleracea var. acephala), mustard (Brassica juncea)], green bean (Phaseolus vulgaris), lettuce (Lactuca sativa), pepper (capsicum annuum), pumpkin (Cucurbita pepo), squash (Cucurbita pepo), strawberry (Fragaria $\times$ ananassa), tomato (Solanum lycopersicum), and watermelon (Citrullus lanatus); 1 acre $=0.4047$ ha. from $\mathrm{PE}$ mulch to $\mathrm{BDM}$ is the reduction in plastic pollution.

Results suggest that BDM users, who have previous experience using PE mulch have larger acreages in fruit and vegetable production $(P=0.002$ for the acreages' comparison), have more years of farming experience $(P=$ 0.089 for the farming experience comparison), and reported having more hours associated with PE mulch removal, and disposal activities $(P=$ 0.065 for the labor hours comparison) than those farmers who had only used PE mulch and have never used BDM (Table 2). Additionally, a larger percentage of BDM users have dumped $(P=0.018)$ or buried $(P=$ 0.063) PE mulch after removing it from the field than those who had only used PE mulch $(P=0.018$ and $P=0.063$, for the dump and bury comparisons, respectively). Finally, a smaller percentage of BDM users have a bachelor's degree or higher compared with those producers who had only used PE mulch $(P=$ 0.036 for the level of education comparison).

The preceding results suggest that there are differences in farm size, years of farming experience, labor hours associated with $\mathrm{PE}$ mulch removal and disposal activities, PE mulch disposal methods, and educational level between growers who have used BDM and those who have primarily used PE mulch for the production of fruit and vegetable crops.

For producers farming larger acreages interested in replacing $\mathrm{PE}$ mulch with comparable mulches in terms of performance, BDM may be the best option because other mulch options are better suited for smaller operations due to the management and amount of labor required to use

Table 3. Polyethylene (PE) mulch and plastic biodegradable mulch (BDM) choices and attributes presented to respondents to a 2019 survey of Tennessee fruit and vegetable farmers about the use of PE mulch and BDM.

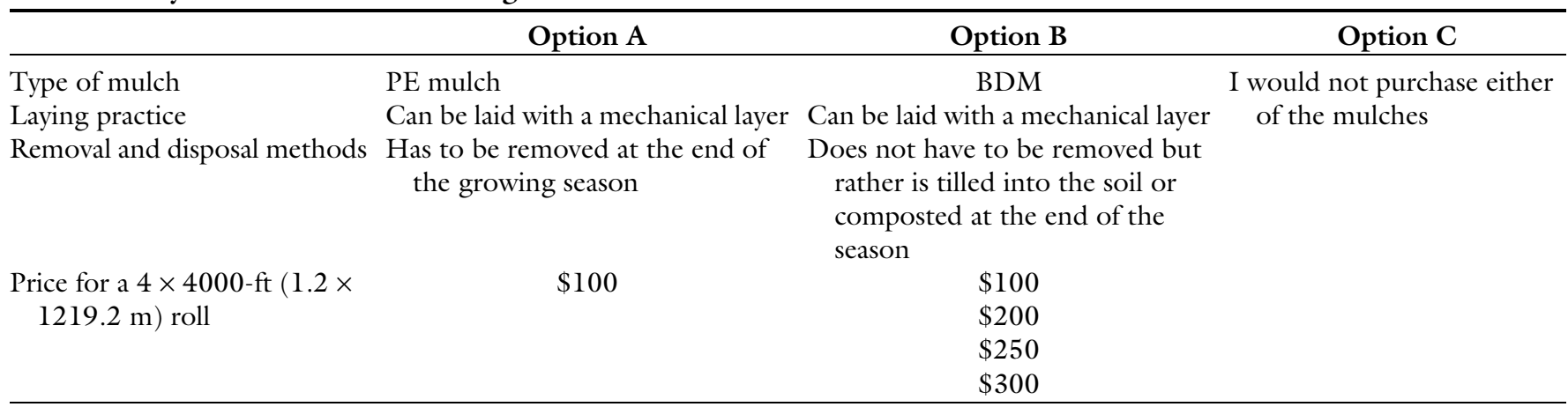


them (Schonbeck, 2015). Producers with more farming experience may be more familiar with both the benefits and challenges associated with the use of PE mulch and therefore may be more likely to look for mulch products that provide similar benefits to PE mulch but eliminate the disadvantages of using this mulch (e.g., labor and disposal cost, plastic pollution) such as BDM.

Labor hours associated with PE mulch removal and disposal could be determined by the farm size but also by PE mulch removal practices. For example, some farmers may retrieve PE mulch fragments left behind after manually removing $\mathrm{PE}$ mulch, whereas others will not retrieve mulch fragments because this is a labor-intensive activity, and they do not see any benefits from doing so (Velandia et al., 2018). Results suggest that those growers who have spent more labor hours in removal and disposal activities may be more interested in looking for mulch alternatives that could reduce these labor hours, such as BDM.

Producers using dumping as a disposal method are likely to incur disposal costs (Velandia et al., 2019) and therefore are more likely to look for alternatives that could eliminate this cost. Those who bury PE mulch after removing it from the field will be able to do so for a limited amount of time if they use PE mulch every year, depending on the space they have on the farm for burying. Eventually, farmers will have to look for alternatives to dispose of PE mulch. BDMs are an attractive substitute for PE mulch because they are tilled into the soil at the end of the season, which reduces labor and disposal costs, as well as potential environmental costs.

Finally, although previous studies suggest more educated farmers would be more likely to adopt sustainable production practices (D'Souza et al., 1993; Liu et al., 2018) such as BDMs, it is important to mention that Sintim et al. (2019) suggested additional information is needed to better assess the longterm effects of BDMs on soil health. Therefore, more educated farmers who may have read or have access to scientific publications may be more hesitant to use BDMs until new information regarding the long-term impacts of BDMs on soil health becomes available.

WiLlingness To USE BDMs. In general, BDMs are more expensive than PE mulch. A $4 \times 4000$ - $\mathrm{ft}$ roll of $\mathrm{BDM}$ can be at least twice as expensive as a roll of PE mulch with the same dimensions (Velandia et al., 2019). As expected, the price of BDM is one of the factors that deter farmers from adopting BDMs (Goldberger et al.,

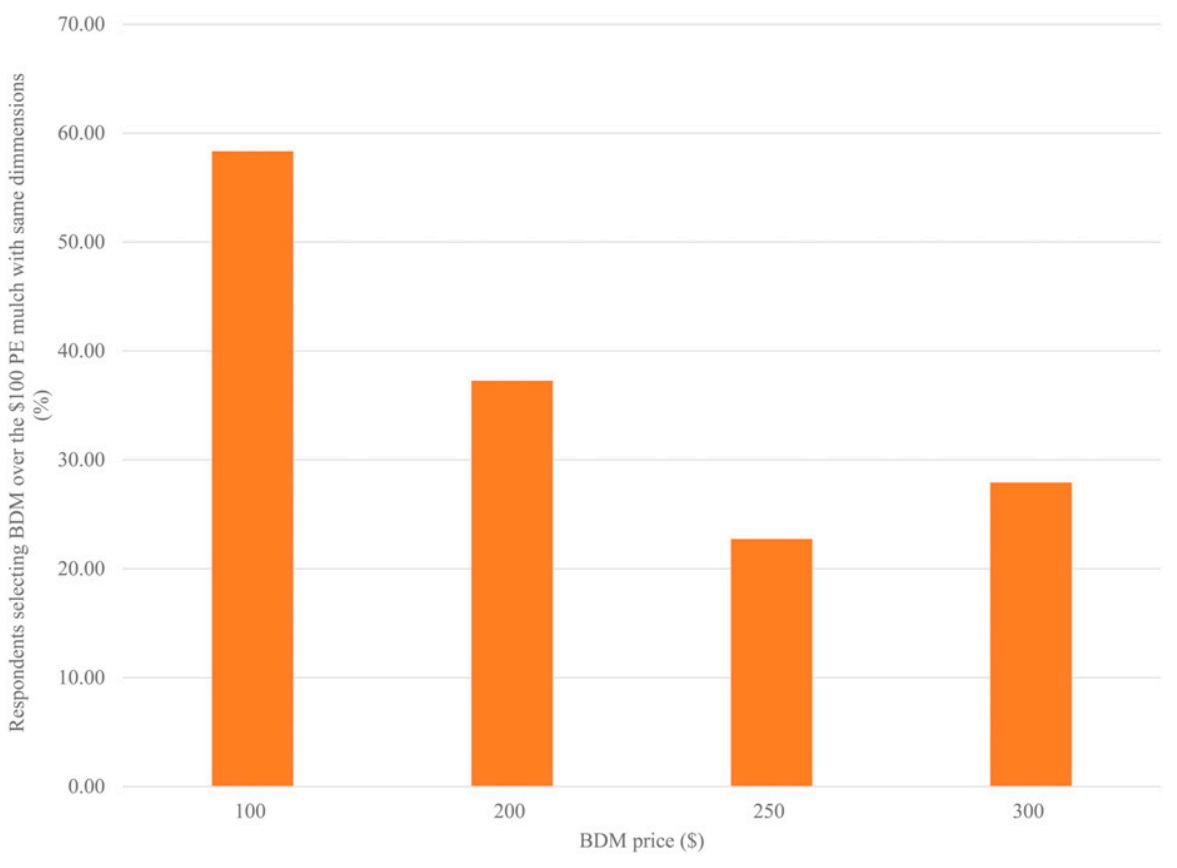

Fig. 4. Percentage of respondents to a 2019 survey of Tennessee fruit and vegetable farmers about the use of polyethylene $(\mathrm{PE})$ mulch and plastic biodegradable mulch (BDM) selecting BDM over PE mulch at various price levels.
2013). Therefore, we explored producer willingness to pay for BDMs and evaluated the difference between what producers were willing to pay for these mulches and the actual market price of these mulch products.

From the 48 respondents who received the $\$ 100$ price option (same price as $\mathrm{PE}$ mulch), $\approx 58 \%$ indicated they would choose BDM over PE mulch (Fig. 4). As expected, as the price of BDM increased, the percentage of respondents choosing BDM over PE mulch decreased. From the 51 respondents who received the $\$ 200$ BDM price option, $\approx 37 \%$ indicated they would choose BDM over PE mulch. From the 44 respondents who received the $\$ 250$ price option, $\approx 23 \%$ indicated they would choose BDM over PE mulch. From the 43 respondents who received the $\$ 300$ price option, $\approx 28 \%$ indicated they would choose $\mathrm{BDM}$ at this price. Those respondents who indicated they would be willing to purchase BDMs at the various price points were willing to use BDM on an average of 6 acres, with the maximum being 60 acres. Similar to the results presented by Scaringelli et al. (2016), the results presented here suggest that some Tennessee fruit and vegetable farmers may be willing to pay a higher price for $\mathrm{BDM}$ than the price of $\mathrm{BDM}$ products that are already available in the market.

These findings are important for mulch manufacturers and input suppliers evaluating the potential market for BDMs in Tennessee. For example, the decision for a local input supplier to carry BDMs will depend on their evaluation of the potential local market for these products. There could be a significant shipping cost associated with BDMs ordered directly from a manufacturer or an online input supplier. Therefore, if input suppliers increase the availability of these products in Tennessee based on the market potential, this will likely reduce the overall cost of BDMs for Tennessee growers and facilitate their adoption on a larger scale (Velandia et al., 2018).

Those respondents who were willing to pay a price greater than $\$ 100$ for BDM, which is the more realistic scenario given current market prices, indicated they would do so mainly because of the labor savings associated with not having to remove 
and dispose of the mulch and also because they believe the use of BDMs could reduce plastic pollution. In contrast, those who express no interest in using BDM at the various price points gave several reasons including belief that BDM will breakdown too fast and therefore will not control weeds, lack of information about BDM, concerns about the effect tilling BDM would have on their soil, and previous negative experiences with mulches that were labeled as biodegradable.

\section{Conclusions}

This research focuses on the use of or interest in using BDMs as an alternative to PE mulch among Tennessee fruit and vegetable growers. Specifically, we focus on growers' use of both PE mulch and BDM, disposal methods for PE mulch, characteristics of BDM users compared with nonusers, and grower willingness to use $\mathrm{BDM}$ at various price levels.

Our results suggest that more than half of the Tennessee fruit and vegetable growers have used PE mulch. Although the majority of survey respondents reported properly disposing of mulches at landfills, there is still a percentage of growers who are burying or burning them on site.

Survey results can help policymakers assess the potential plastic pollution associated with the use of PE mulch in Tennessee, as well as evaluate incentives than can promote the use of BDM among Tennessee fruit and vegetable growers. For example, this survey provides the first estimate regarding Tennessee fruit and vegetable farmer use and disposal of PE mulch, which gives policymakers an idea of the potential soil plastic pollution they could be facing in the future. Furthermore, the survey data are the first of their kind in Tennessee in assessing fruit and vegetable producers' interest in and willingness to pay for more environmentally friendly mulch options such as BDMs. Interest in and willingness to pay for BDM by Tennessee fruit and vegetable farmers could help policymakers think about incentives and programs that could facilitate the access to and adoption of BDM by these growers.

Information from this survey can also help input suppliers evaluate interest in BDMs among Tennessee fruit and vegetable growers, and therefore, help them evaluate the market potential for BDMs in Tennessee. In general, our results suggest that Tennessee fruit and vegetable growers are not very familiar with BDMs. Therefore, manufacturers and university extension still have work to do in educating farmers about this type of mulch.

\section{Literature cited}

D'Souza, G., D. Cyphers, and T. Phipps. 1993. Factors affecting the adoption of sustainable agricultural practices. Agr. Resour. Econ. Rev. 22(2):159-165.

Dillman, D.A., J.D. Smyth, and L.M. Christian. 2009. Internet, mail, and mixed-mode surveys. The tailored design method. Wiley, Hoboken, NJ.

Emmert, E.M. 1957. Black polyethylene for mulching vegetables. Proc. Amer. Soc. Hort. Sci. 69:464-469.

Feldman, R.S., C.E. Holmes, and T.A. Blomgren. 2000. Use of fabric and compost mulches for vegetable production in a low tillage permanent bed system: Effects on crop yield and labor. Amer. J. Altern. Agr. 15(4):146-153.

Fessenden, M. 2015. Most plastic trash comes from farms. 12 Dec. 2019. <https:// www.smithsonianmag.com/smart-news/ most-plastic-trash-comes-farms-heres-whatwere-trying-do-about-it-180954873/> .

Goldberger, J., L.W. DeVetter, and K.E. Dentzman. 2019. Polyethylene and biodegradable plastic mulches for strawberry production in the United States: Experiences and opinions of growers in three regions. HortTechnology 29:619-628.

Goldberger, J., R. Jones, C. Miles, R. Wallace, and D. Inglis. 2013. Barriers and bridges to the adoption of biodegradable plastic mulches for U.S. specialty crop production. Renew. Agr. Food Syst. 30(2): 143-153.

Hayes, D.G. and M. Flury. 2018. Summary and assessment of EN 17033:2018, a new standard for biodegradable plastic mulch films. Rpt. No. EXT-2018-01. 1 Jan. 2020. <https://ag.tennessee.edu/ biodegradablemulch/Documents/EU\% 20regs\%20factsheet.pdf>.

Kasirajan, S. and M. Ngouajio. 2012. Polyethylene and biodegradable mulches for agricultural applications: A review. Agron. Sustain. Dev. 32(2):501-529.

Liu, E.K., W.Q. He, and C.R. Yan. 2014. "White revolution" to "white pollution"-Agricultural plastic film mulch in China. Environ. Res. Lett. 9(9):091001.

Liu, T., R.J.F. Bruins, and M.T. Heberling. 2018. Factors influencing farmers' adoption of best management practices: A review and synthesis. Sustainability 10(2):432456.

Miles, C. 2017. Oxo-degradable plastics risk environmental pollution. Rpt. No. FA-2017-01. 21 Jan. 2020. <https://ag. tennessee.edu/biodegradablemulch/ Documents/oxo\%20plastics.pdf>.

Moore, J. and A. Wszelaki. 2016. Plastic mulch in fruit and vegetable production: Challenges for disposal. Rpt. No. FA-201602. 12 Dec. 2019. <https://ag.tennessee. edu/biodegradablemulch/Documents/ Plastic_Mulch_in_Fruit_and_Vegetable_ Production_12_20factsheet.pdf $>$.

Scaringelli, M.A., G. Giannoccaro, M. Prosperi, and A. Lopolito. 2016. Adoption of biodegradable mulching films in agriculture: Is there a negative prejudice towards materials derived from organic wastes? Ital. J. Agron. 11(2):619-628.

Schonbeck, M. 2015. Mulching for weed management in organic vegetable production. eXtension eOrganic 4870. 12 Dec. 2019. <https://tinyurl.com/y4qxsl7j>.

Shogren, R.L. and R.C. Hochmuth. 2004. Field evaluation of watermelon grown on paper-polymerized vegetable oil mulches. HortScience 39:1588-1591.

Sintim, H.Y., S. Bandopadhyay, M.E. English, A.I. Bary, J.M. DeBruyn, S.M. Schaeffer, C.A. Miles, J.P. Reganold, and M. Flury. 2019. Impacts of biodegradable plastic mulches on soil health. Agr. Ecosyst. Environ. 273(1):36-49.

StataCorp. 2013. Stata base reference manual release 13. StataCorp., College Station, TX.

U.S. Department of Agriculture. 2019. 2017 Census of agriculture. Census data query tool (CDQT). 12 Dec. 2019. <https://www. nass.usda.gov/Publications/AgCensus/ 2017/Online_Resources/Census_Data_ Query_Tool/index.php>.

Valavanidis, A., N. Iliopoulos, G. Gotsis, and K. Fiotakis. 2008. Persistent free radicals, heavy metals and PAHs generated in particulate soot emissions and residue ash from controlled combustion of common types of plastic. J. Hazard. Mater. 156(1-3):277-284.

Velandia, M., A. Smith, A. Wszelaki, S. Galinato, and T. Marsh. 2018. The economics of adopting biodegradable plastic mulch films. Univ. Tennessee Ext. W650. 12 Dec. 2019. <https://bit.ly/2OfzOPe>.

Velandia, M., A. Smith, A. Wszelaki, and S. Galinato. 2019. The economic feasibility of adopting plastic biodegradable mulches in pumpkin production. Univ. Tennessee Ext. W822. 12 Dec. 2019. <https://bit.ly/2Y5qPXa>. 